\title{
The bushmeat boom and bust in West and Central Africa
}

\author{
Richard F. W. Barnes
}

Abstract Poor soils and high rainfall mean that the high productivity of the forests, an assumption that drives the development of the forest zone, is an illusion. The potential of the forests to produce meat, from wild or domestic herbivores, is limited. Growing human populations and shrinking forests accelerate pressures on forest resources faster than national statistics indicate. A simulation model demonstrates the effects of growing hunting pressure on one monkey and two duiker species. A version of this model that includes random variation shows that large harvests can be obtained for many years, but that a population collapse can happen suddenly; there is no period of gradually declining harvests. The accelerating hunting pressure in a zone of low productivity, shrinking habitat for monkeys and antelopes, the dynamics of non-linear systems, and natural environmental variation that affects reproduction and survival will lead to a collapse of hunted populations across the forest zone. We are now seeing the bushmeat boom and soon we will see the bushmeat bust.

Keywords Bushmeat, forests, harvests, hunting, model, West and Central Africa.

\section{Introduction}

Hunting is part of the culture of the people in the forest zone of West and Central Africa (Fig. 1) because wild meat, or 'bushmeat', is their most important source of protein (Asibey, 1974; Ntiamoa-Baidu, 1987; Anadu et al., 1988; Lahm, 1993; Wilkie \& Carpenter, 1999; Bakarr et al., 2001). Although densities of subsistence farmers and hunters in the lowland tropical forests were low in the past (Barnes \& Lahm, 1997; Robinson \& Bennett, 2000a), they are now increasing rapidly. Roads are penetrating the forest zone, and logging companies are moving into new concessions, bringing hunters into forests that were long undisturbed (Tutin \& Fernandez, 1987; Wilkie et al., 1992; Oates, 1999). Hunting technology has changed, with the use of shotguns having become ubiquitous since the end of the colonial period (Lahm, 1993), and the amount of bushmeat coming out of the forest zone has increased dramatically in the last decade (Bowen-Jones \& Pendry, 1999; Wilkie \& Carpenter, 1999; Robinson \& Bennett, 2000b; Bakarr et al., 2001). Farmers are also moving into the forest zone, for example to grow cocoa (Oates, 1995, 1999), and in West Africa the forests have been fragmented into isolated patches (Parren \& de Graaf, 1995).

Richard F. W. Barnes Africa Program, Conservation International, Washington DC, USA. E-mail: rfbarnes@ucsd.edu

Present address: Biology Division 0116, University of California at San Diego La Jolla, CA 92093-0116, USA

Received 14 June 2001. Revision requested 11 September 2001. Accepted 16 November 2001

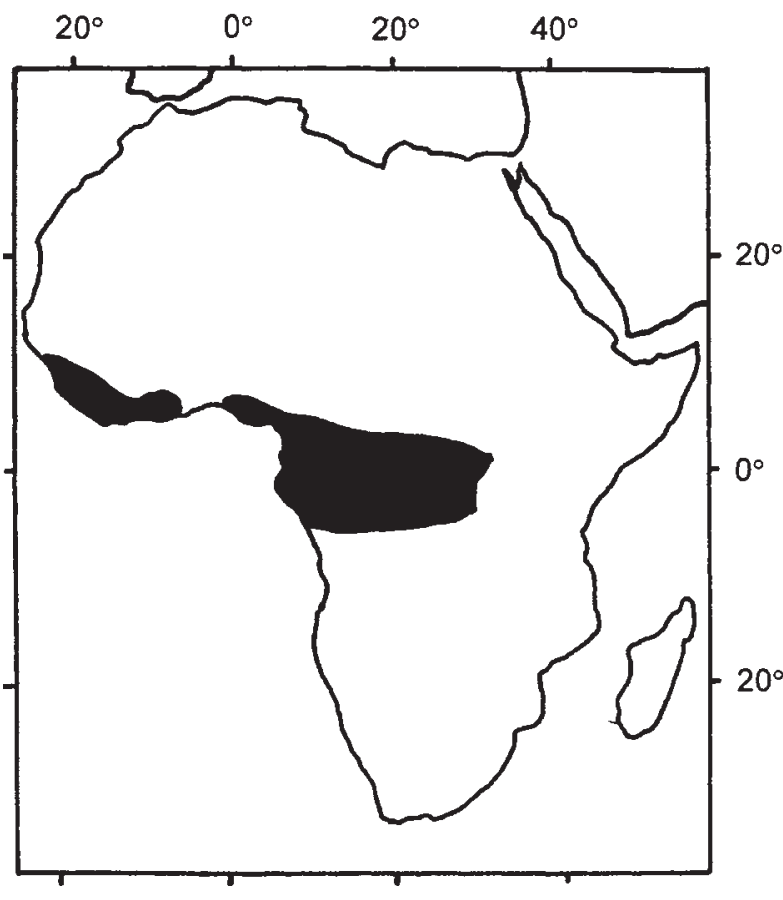

Fig. 1 Map of Africa showing the Guinea-Congolian forests of West and Central Africa (after White, 1983).

There is a common misconception that the African forests are fertile and productive. To understand the forest's capacity to produce a bushmeat harvest one must examine the relationship between geology, rainfall and mammalian biomass (Barnes \& Lahm, 1997). The forests of West and Central Africa lie mainly upon granitic shields and Kalahari sands that produce poor 
soils (Bell, 1982). The heavy rain leaches away the few nutrients in these soils and renders them relatively infertile. Trees are the plants that grow best under such conditions (Bell, 1982). Only c. $2 \%$ of the biomass of a tropical forest tree is foliage (Fittkau \& Klinge, 1973), and much of this is protected from herbivorous animals, both invertebrate and vertebrate, by toxic secondary compounds (McKey et al., 1978; Coley \& Barone, 1996). Thus only a small proportion of the forest vegetation can be eaten by mammals and birds.

Most of the energy in the forest passes through the microbial decomposer chain, from live plants to dead organic matter that decomposes, instead of energy passing from plants to herbivores that can be harvested by hunters, as happens in the savannah (Fittkau \& Klinge, 1973). The energy that passes through the animal trophic level goes mainly through invertebrates rather than vertebrates (Fittkau \& Klinge, 1973). Therefore, the forest zone supports a much lower mammalian biomass than do other ecological zones. In the absence of hunting, the peak mammalian biomass on basement and Kalahari sands occurs where mean annual rainfall is $700-1,300 \mathrm{~mm}$, i.e. outside the forest zone (Fig. 2).

The mammalian fauna in the forest has a high proportion of large-bodied species that can tolerate poor-quality forage (Bell, 1982; White, 1994): buffaloes, elephants, gorillas, chimpanzees, mandrills, drills and bushpigs. Large animals can digest poor-quality plant matter and they can travel widely in search of fruits, but secondary production (i.e. meat production) is inversely related to body size. Furthermore, a significant proportion of forest mammals are primates, which have a low rate of production for a given body size (Robinson \& Redford, 1986).

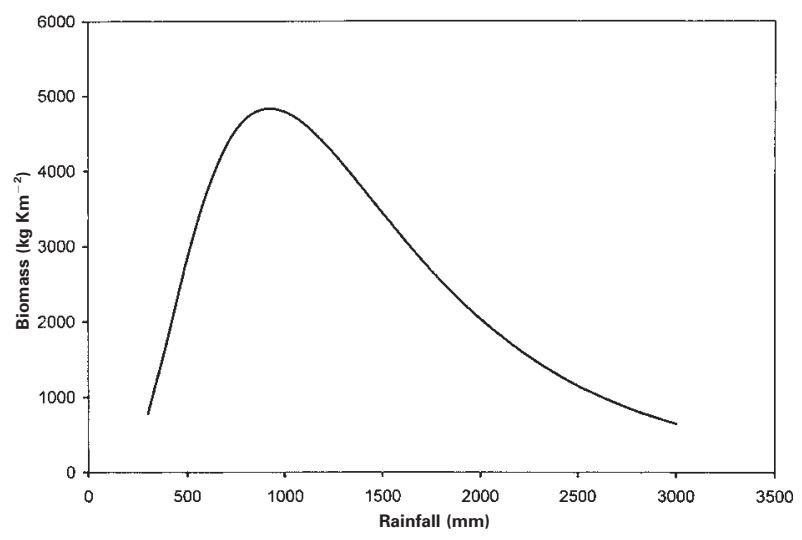

Fig. 2 Variations in wild herbivore biomass along the rainfall gradient for sites on basement and Kalahari sands, in the absence of hunting, according to the model from Barnes \& Lahm (1997). Forests are found in West Africa where rainfall exceeds about 1,300 mm per annum (Hall \& Swaine, 1981), and they are found in Central Africa where rainfall exceeds 1,600 mm per annum (White, 1983)
The combination of the low biomass of mammalian herbivores in the forest, compared to less humid habitats, and the low rates of meat production of forest mammals, results in a low potential meat harvest in the forest zone. However, the human population is growing rapidly, from both reproduction and immigration. In this paper the consequences of the interaction between growing hunting pressure and fluctuating prey populations are illustrated by a simulation model.

\section{A model of the effect of increasing hunting rates upon forest mammals}

The effects of increasing hunting pressure on a bushmeat species can be predicted by a simple model (Caughley et al., 1990):

$N_{t+1}=\left(N_{t}-Y_{t}\right) \exp \left[r_{m}\left(1-N_{t} / K\right)\right]$

where $N_{t}$ is the number of animals in year $t, N_{t+1}$ is the number in the following year, $K$ (carrying capacity) is the equilibrium population size in the absence of hunting, $Y_{t}$ is the number of animals harvested, and $r_{m}$ is the intrinsic rate of natural increase (the balance of births and deaths). Note that $1-N_{t} / K$ is a density-dependent term; as the population falls the per-capita reproductive rate rises. The harvest depends upon both the number of animals present and the hunting effort:

$Y_{t}=E_{t} N_{t}$

where $E_{t}$ is the hunting effort, which increases each year as

$E_{t}=\left(Y_{0} / N_{0}\right) \exp (f t)$

where $f$ is the rate of change of effort, and $Y_{0}$ and $N_{0}$ are the initial harvest and population size respectively.

Three common prey species were selected for this example: the spot-nosed monkey Cercopithecus nictitans, which is common in the Central African forests; the medium-sized bay duiker Cephalophus dorsalis; and the small blue duiker Cephalophus monticola. Both duikers are common in the forests of West and Central Africa (Kingdon, 1997).

Mean body weights were taken from Fa \& Purvis (1997): $4.967 \mathrm{~kg}$ for C. nictitans, $20.350 \mathrm{~kg}$ for C. dorsalis, and $4.900 \mathrm{~kg}$ for C. monticola. The intrinsic rate of natural increase, $r_{m}$, was estimated for each species using Robinson \& Redford's (1986) equations, for primates and ungulates, that relate $r_{m}$ to body weight, giving values of $0.13,0.72$, and 1.67 per annum respectively.

The initial population for each species was set at 1,000 animals. $K$ was set at 1,200 for each species. The initial harvest was $1 \%$ per annum. The rate of change of hunting effort was set at twice the rate of human population increase in West Africa (i.e. $f=0.05$ ) to 
account for reproduction, immigration, and increasing disturbance from activities such as logging. The model was run separately for each species.

Under these conditions, the harvest of $C$. nictitans increased steadily to reach a peak after about 50 years, and then declined (Fig. 3a). The decline phase was more rapid than the increase, because of the greater hunting effort in the later years. The harvest of the duiker species peaked later and declined more rapidly than that of the monkey. The C. dorsalis harvest peaked in year 71, while that of the smaller C. monticola peaked in year 80 . The time between peak harvest and extinction was 31 years
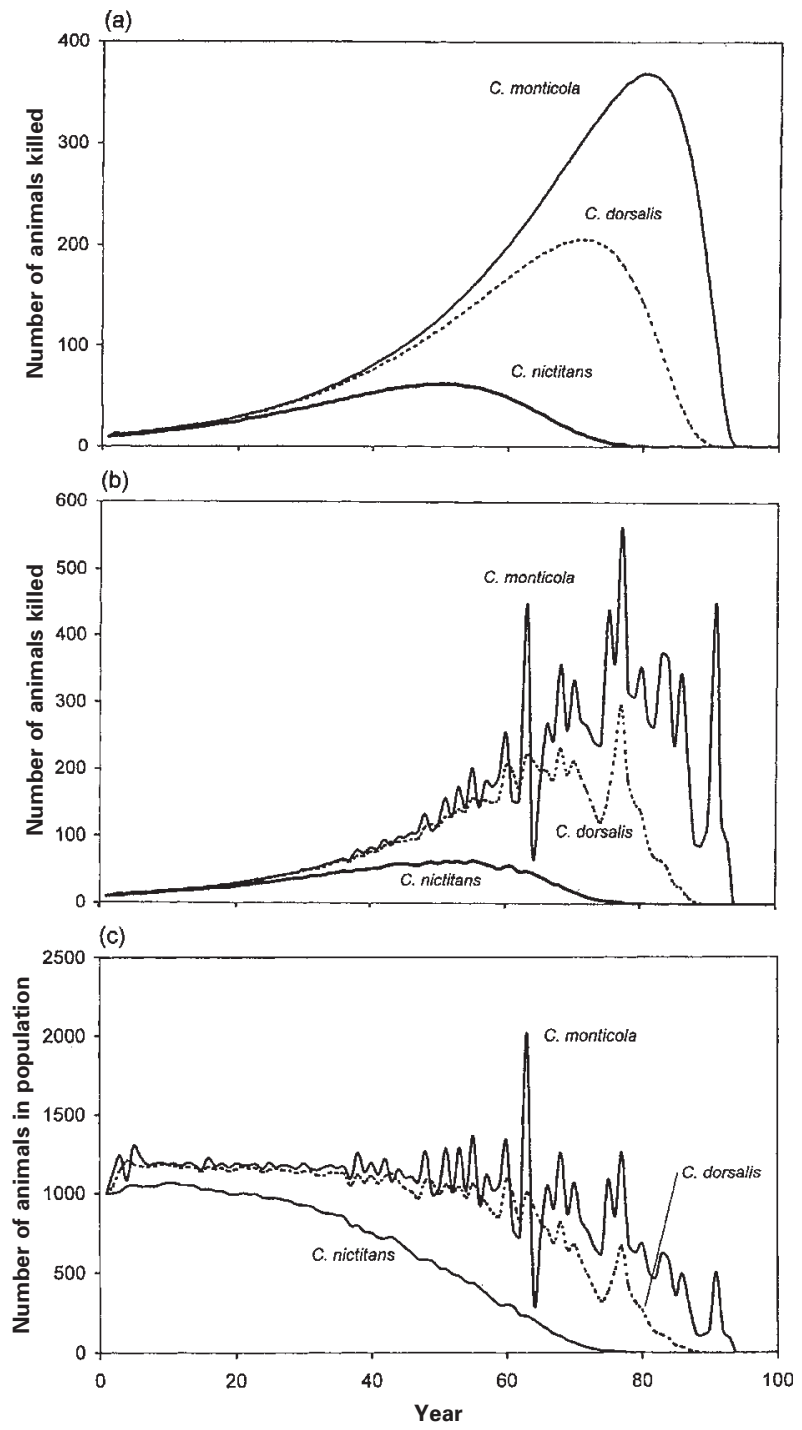

Fig. 3 The effects of increasing hunting pressure on one monkey and two duiker species simulated by harvest models adapted from Caughley et al. (1990). (a) Harvests predicted by the deterministic model. (b) Harvests predicted by the model that incorporates random variation. (c) Numbers of animals in each population predicted by the harvest model that incorporates random variation. for the monkey, compared to 20 years for C. dorsalis, and 14 years for $C$. monticola. This difference comes about because the duiker species reproduce more rapidly than the monkey and so are able to sustain the increasing hunting for longer, but when the decline does start the hunting pressure is at a high level, causing a rapid collapse.

Note that although the body weights of $C$. nictitans and C. monticola are similar, the differences in the life history strategies of primates and ungulates mean that duikers reproduce rapidly and can therefore sustain a much greater hunting pressure than monkeys. The simulations produced a harvest of 2,683 monkeys (a total carcass weight of $13,326 \mathrm{~kg}$ ) over 80 years compared to 13,226 duikers (a total carcass weight of $64,807 \mathrm{~kg}$ ) over 93 years.

However, the assumption of a constant value of $r_{m}$ is unrealistic. Births and deaths, and hence $r_{m}$, will vary from year to year as a consequence of changes in weather, food supply (e.g. fruit abundance), disease, parasites, and mortality from non-human predators. Adding a stochastic term can provide useful insights into the dynamics of the system, and so the model was modified by introducing a random variable $V$ into the equation:

$N_{t+1}=\left(N_{t}-Y_{t}\right) \exp \left[\left(r_{m} V\right)\left(1-N_{t} / K\right)\right]$.

The model was run with $V$ as a random normal deviate with a mean of 1 and a variance of 0.25 . Thus, the rate of increase $\left(r_{m} V\right)$ can vary from 0 to double its mean value, with most values grouped about the mean because of the normal distribution. For example, the mean value of $r_{m} V$ for the monkey was 0.13 and three quarters of the values fell between 0.06 and 0.20 .

For C. nictitans, the results of the stochastic model were similar to the first model. In contrast, the duikers, especially the smaller species, showed much interannual variability in harvest (Fig. 3b). C. dorsalis harvest peaked in year 77 and then declined steeply to zero over the next 13 years. For C. monticola the collapse was more precipitous: the harvest was high in year 91, but three years later the population was extinct.

Population size (stock) showed a similar pattern. There was little between-year variation in monkey population size, except for the general downward trend, but the duikers, especially the smaller species, showed much annual variation in numbers (Fig. 3c).

\section{Discussion}

The human population of sub-Saharan Africa grew from about 84 million in 1900 to 168 million in 1950 and to 612 million in 2000 (McEvedy \& Jones, 1978; United Nations, 2000). The mean rate of human population 
growth for the West African countries is $2.6 \%$ per annum (United Nations, 2000) but the rate is higher in the forest zone because of internal migration (Oates, 1995, 1999). If the number of people is growing while the area of forest is shrinking, then the human pressures on each remaining square kilometre of forest will increase more rapidly than $2.6 \%$ per annum. Furthermore, as the forest area diminishes, the perimeter/area ratio will increase, making access easier. Thus national statistics of the growth of human populations obscure the accelerating pressures upon the forest.

\section{Mammalian abundance}

The relationship between mammalian biomass and rainfall (Fig. 2) suggests that one would obtain better bushmeat harvests from the savannahs than the forest zone. For example, the average biomass in the forest zone is less than $2,600 \mathrm{~kg} \mathrm{~km}^{-2}\left(1,777 \mathrm{~kg} \mathrm{~km}^{-2}\right.$ for the lands between the 1,800 and $2,500 \mathrm{~mm}$ isohyets). In contrast, where rainfall is $c$. $700-1,300 \mathrm{~mm}$ the mammalian biomass averages about $4,500 \mathrm{~kg} \mathrm{~km}^{-2}$. In West Africa the lands between the 700 and $1,300 \mathrm{~mm}$ isohyets are the forest/savannah transition zone and the Guinea and Sudanian savannahs. Although these areas once supported a rich mammalian fauna, most of the larger wild animals have disappeared over centuries of high human densities and heavy hunting (Sayer, 1977; Ciofolo, 1995). The fauna of the forest zone remained, at least until recently, because of the lower human density, but with increasing disturbance these populations are now being heavily exploited. Human densities are much lower in Central Africa than in West Africa, and there may still be some potential to manage wildlife for meat production in the forest/savannah ecotone or in the savannahs, for instance in central and northern Cameroon, the Central African Republic and southern Chad.

It is often suggested that meat from domestic animals could reduce the demand for bushmeat. However, the same determinants of wild herbivore biomass also apply to domestic animals (Barnes \& Lahm, 1997). The ability of the forest zone to produce meat from wild or domestic herbivores is limited, whether the forest remains or has been felled (Barnes \& Lahm, 1997).

\section{Limitations of models}

This harvest model is conservative because it probably underestimates the growth in hunting pressure. Here $f$ (the rate of change of effort) was set at 0.05; in their study of ivory harvests since 1950, Caughley et al. (1990) deduced that $f$ must lie between 0.080 and 0.085 for East Africa, and they estimated $f=0.0573$ for the whole continent. Hunting effort was assumed to grow steadily, whereas it may actually increase in jumps. For example, hunting may surge when a new road or railway is built or an old road is paved, or if a logging company opens a new concession. After the collapse of the price of oil in 1986, unemployment in Gabon forced many young men to return to their natal villages where hunting was the only source of income (Lahm, 1993). Other changes in the national economy, such as increasing disposable incomes in the towns, may stimulate the urban demand for bushmeat.

The density-dependent term in the harvest model caused the reproductive rate to increase as animal numbers fell. However, at very low densities it is likely that the reproductive rate will decline, for example if oestrous females cannot find mates, thus hastening the collapse of heavily-hunted populations. Allee (1938) suggested that each species has a minimum population size, and recovery is impossible when a population drops below that number.

Simulation models are gross simplifications of reality but they can reveal the most important trends within a system. Examples from pelagic fisheries show that this harvest model does indeed illustrate the dynamics of a population under increasing exploitation. Fig. $3 \mathrm{~b}$ is similar to the trend of the Pacific sardine Sardinops sagax fishery that was characterised by modest harvests that expanded as increasing numbers of boats joined in and a market developed (Fig. 4). An annual harvest averaging 533,000 tons was maintained for 12 years and then the fishery collapsed (Radovich, 1981; Johnson \& Stickney, 1989). The Peruvian anchovy Engraulis ringens catch expanded from less than half a million tonnes in 1955 to over 12 million tonnes in 1970 and then collapsed, showing a curve similar to Fig. 3b (Glantz, 1981). The anchovy collapse was associated with poor recruitment

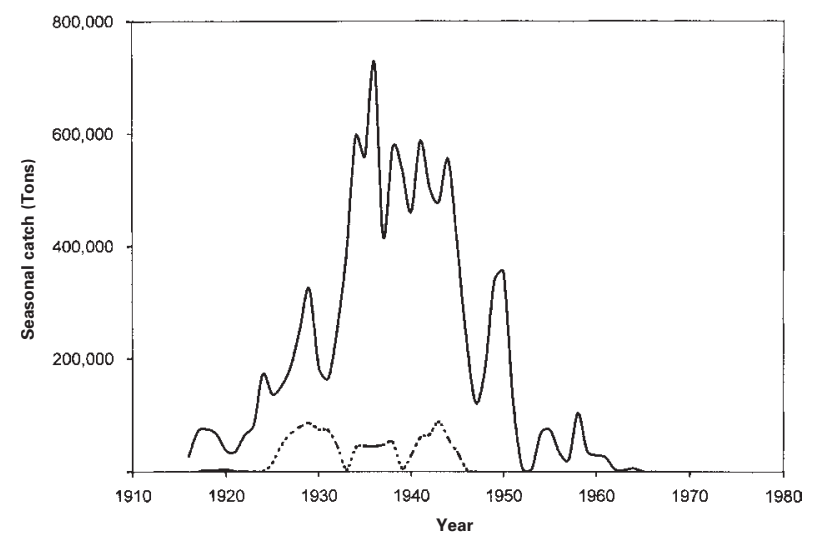

Fig. 4 The trend in the harvest of the Pacific sardine fishery between 1916 and 1968 (from Radovich, 1981). The upper line shows the California catch, and the broken lower line shows the Pacific Northwest catch. 
in 1971 and the 1972-73 El Nino, as well as overfishing (Glantz, 1981), illustrating how environmental stochasticity can interact with human activities to destroy a resource.

\section{Multi-species hunting}

It is the large-bodied animals with their lower reproductive rates that can least sustain heavy hunting (Fig. 3). In a system where the hunter concentrates on only one large-bodied species, continued hunting ceases to be worthwhile when prey abundance drops below a certain threshold. However, hunters in the forest do not specialize, they shoot any animal they see and take whatever is caught in a snare. When large animals become scarce, hunting will still be worthwhile because small animals, such as $C$. monticola, will still be common. The hunter will take mainly small animals but will shoot any large ones he encounters, so the pressure on large animals will remain high. Therefore in a multi-species hunting system, such as the West and Central African forests, large animals are more likely to be driven to local extinction than in a system where they are the only prey.

\section{Implications for monitoring}

Evaluating the status of populations of forest animals is difficult because the numbers vary from one year to the next (Fig. 3c). Thus, the status of prey species in a particular forest cannot be determined by conducting a single survey, which may explain why estimates of duiker density vary greatly in the Ituri Forest (Wilkie \& Carpenter, 1999). Surveys in several consecutive years will be necessary to evaluate the status of each species at a particular site. Although monkeys can be expected to show less annual variation in numbers than duikers (Fig. 3c), estimates of population size will have a large variance because monkeys live in groups that may or may not fall within the survey transects. The large variance will reduce the statistical power of monitoring schemes, that is, the probability that they will detect trends in monkey numbers (Gerrodette, 1987).

Densities of forest animals also vary with distance from sources of human disturbance (Barnes et al., 1991; Lahm, 1993; Barnes et al., 1997; Lahm et al., 1998; unpublished examples in Wilkie \& Carpenter, 1999). Thus spatial and temporal variations in the abundance of mammals, and the need to include distance to roads or villages as a covariate, will make monitoring programmes expensive because of the need for intensive sampling in any particular forest block. On the other hand, a gradient in densities, as seen for monkeys in the Central African forests for example (Lahm et al., 1998), could be used as an index of hunting pressure. For elephants at least, the slope of the gradient differs between lightly and intensely hunted areas (Michelmore et al., 1994), and the same is probably true of primates.

\section{Harvesting in a Fluctuating Environment}

The model shows that the prey species could produce large harvests for many years: but if hunting effort is steadily increasing, a sudden collapse of the resource is inevitable (Fig. 3b). When the supply declines, continued demand may force prices up, so intensifying hunting pressure and driving the prey populations to extinction.

Intuitively, we assume that a decline caused by overhunting will occur over several years, allowing steps to be taken to reduce the annual harvest. It is true that the populations will decline slowly (Fig. 3c); however, as in a pelagic fishery, one can easily count the harvest but one has little idea of what is happening to the stock. If large harvests are obtained year after year then, as Fig. $3 b$ reveals, there may be little warning of the impending collapse. A sudden collapse will occur when heavy hunting coincides with a year of poor fruiting or disease.

The harvest per hunter will fall as more hunters join in, even though the total harvest remains high. If an individual's perception of this decline is obscured by the year-to-year variations in his hunting success, he will continue to hunt and thus contribute to the overall heavy hunting pressure, instead of shifting to some other activity.

In this model, the increase in hunting pressure and the density-dependence are non-linear. Unpleasant surprises are a feature of non-linear systems (Barnes, 1983; May, 1986; Caughley et al., 1990). In this case there are several negative factors acting simultaneously: growing human populations in the forest zone, loss of habitat as forest is replaced by farms and villages, spread of roads and vehicles, expansion of logging, increasing aspirations and need for cash among rural people, and growing urban prosperity that stimulates more demand for bushmeat. Random environmental variation, when combined with the non-linearities, adds to the unpredictability, making it difficult to devise sustainable harvest schemes. Regular annual quotas may be in operation for many years, but a year of poor breeding for the prey population, or a small increase in immigrant farmers to the area, may push the system to an unexpected collapse.

Biologists seek the Holy Grail of sustainability (Robinson \& Bennett, 2000b; Bakarr et al., 2001), but sustainable harvests may well be a mirage. Maximum sustained yield (MSY) eludes natural resource managers in systems where overexploitation is obscured by random variation, and carefully controlled experiments cannot be conducted (Ludwig et al., 1993). 
Different forests, or different districts and countries, may be in different phases of the syndrome of growing harvests followed by collapse, illustrated by Fig. 3b. Harvests in the West African forests, which have suffered a much higher rate of deforestation and fragmentation, are likely to be closer to collapse than those of Central Africa. For example, the forests of south-western Ghana and neighbouring Côte d'Ivoire have already lost a large part of their primate fauna (Struhsaker \& Oates, 1995; McGraw et al., 1998; Oates et al., 2000), whereas primates are still common in much of the Central African forests. Like the Pacific sardine fishery, the bushmeat situation is a classic case of boom-and-bust. We are now seeing the bushmeat boom, and soon we will see the bushmeat bust.

\section{Conclusion}

I have argued that human pressures on bushmeat populations are growing more rapidly than national population statistics suggest, that forests produce smaller harvests than people assume, that the growing hunting pressure, in conjunction with a system of non-linear relationships and a fluctuating environment, will produce a period of good bushmeat harvests that will be followed by a collapse, and that the collapse will be sudden. What are the implications for wildlife managers? Firstly, we should pay more attention to the savannahs and forest/savannah ecotones in Central Africa where human densities are still modest and which are better suited ecologically for meat production. Secondly, no government wildlife agency or non-governmental organisation will be able to address the bushmeat problem during the phase of good harvests, because nobody will believe that there is a problem. Thirdly, by the time the collapse is noticed, it may well be too late to do anything about it.

\section{Acknowledgements}

I thank Karen Barnes, Pascal Gagneux, John Hutton, Sally Lahm, Jim Moore and David Wilkie for criticising an earlier version of the manuscript.

\section{References}

Allee, W.C. (1938) The Social Life of Animals. W.W. Norton, New York.

Anadu, P.A., Elamah, P.O. \& Oates, J.F. (1988) The bushmeat trade in southwestern Nigeria: a case study. Human Ecology, 16, 199-208.

Asibey, E.O.A. (1974) Wildlife as a source of protein in Africa south of the Sahara. Biological Conservation, 6, 32-39.
Bakarr, M.I., da Fonseca, G.A.B., Mittermeier, R., Rylands, A.B. \& Paenemilla, K.W. (2001) Hunting and Bushmeat Utilization in the African Rain Forest: Perspectives Towards a Blueprint for Conservation Action. Advances in Applied Biodiversity Science, Number 2, Conservation International, Washington DC.

Barnes, R.F.W. (1983) Effects of elephant browsing on woodlands in a Tanzanian National Park: measurements, models, and management. Journal of Applied Ecology, 20, 521-540.

Barnes, R.F.W. \& Lahm, S.A. (1997) An ecological perspective on human densities in the central African forests. Journal of Applied Ecology, 34, 245-260.

Barnes, R.F.W., Barnes, K.L., Alers, M.P.T. \& Blom, A. (1991) Man determines the distribution of elephants in the rain forests of northeastern Gabon. African Journal of Ecology, 29, 54-63.

Barnes, R.F.W., Beardsley, K., Michelmore, F., Barnes, K.L., Alers, M.P.T. \& Blom, A. (1997) Estimating forest elephant numbers with dung counts and a geographic information system. Journal of Wildlife Management, 61, 1384-1393.

Bell, R.H.V. (1982) The effect of soil nutrient availability on community structure in African ecosystems. In Ecology of Tropical Savannahs (eds B.J. Huntley \& B.H. Walker), pp. 193-216. Springer-Verlag, Berlin.

Bowen-Jones, E. \& Pendry, S. (1999) The threat to primates and other mammals from the bushmeat trade in Africa, and how this threat could be diminished. Oryx, 33, 233-246.

Caughley, G., Dublin, H. \& Parker, I. (1990) Projected decline of the African elephant. Biological Conservation, 54, 157-164.

Ciofolo, I. (1995) West Africa's last giraffes: the conflict between development and conservation. Journal of Tropical Ecology, 11, 577-588.

Coley, P.D. \& Barone, J.A. (1996) Herbivory and plant defenses in tropical forests. Annual Review of Ecology and Systematics, 27, 305-335.

Fa, J.E. \& Purvis, A. (1997) Body size, diet and population density in Afrotropical forest mammals: a comparison with neotropical species. Journal of Animal Ecology, 66, 98-112.

Fittkau, E.J. \& Klinge, H. (1973) On biomass and trophic structure of the central Amazonian rain forest ecosystem. Biotropica, 5, 2-14.

Gerrodette, T. (1987) A power analysis for detecting trends. Ecology, 68, 1364-1372.

Glantz, M.H. (1981) Considerations of the societal value of an El Nino forecast and the 1972-73 El Nino. In Resource Management and Environmental Uncertainty (eds M.H. Glantz \& J.D. Thompson), pp. 449-476. John Wiley \& Sons, New York.

Hall, J.B. \& Swaine, M.D. (1981) Distribution and Ecology of Vascular Plants in a Tropical Rain Forest. Forest Vegetation in Ghana. Junk, The Hague.

Johnson, F.G. \& Stickney, R.R. (1989) Fisheries: Harvesting Life from Water. Kendall/Hunt Publishing Co., Dubuque, Iowa.

Kingdon, J. (1997) The Kingdon Field Guide to African Mammals. Academic press, San Diego.

Lahm, S.A. (1993) Ecology and economics of human/wildlife interaction in Gabon. PhD thesis, New York University, NY.

Lahm, S.A., Barnes, R.F.W., Beardsley, K. \& Cervinka, P. (1998) A method for censusing the greater white-nosed monkey in north-eastern Gabon using the population density gradient in relation to roads. Journal of Tropical Ecology, 14, 629-643. 
Ludwig, D., Hilborn, R. \& Walters, C. (1993) Uncertainty, resource exploitation, and conservation: lessons from history. Science, 260, 17-18.

May, R.M. (1986) When two and two do not make four: nonlinear phenomena in ecology. Proceedings of the Royal Society, London Series B, 228, 241-266.

McEvedy, C. \& Jones, R. (1978) Atlas of World Population History. Penguin, London.

McGraw, W.S., Monah, I.T., \& Abedi-Lartey, M. (1998) Survey of endangered primates in the forest reserves of eastern Cote d'Ivoire. African Primates, 3, 22-25.

McKey, D., Waterman, P.G., Mbi, C.N., Gartlan, J.S. \& Struhsaker, T.T. (1978) Phenolic content of vegetation in two African rain forests: ecological implications. Science, 202, 61-64.

Michelmore, F., Beardsley, K., Barnes, R.F.W. \& DouglasHamilton, I. (1994) A model illustrating the changes in forest elephant numbers caused by poaching. African Journal of Ecology, 32, 89-99.

Ntiamoa-Baidu, Y. (1987) West African wildlife: a resource in jeopardy. Unasylva, 39, 27-35.

Oates, J.F. (1995) The dangers of conservation by rural development - a case study from the forests of Nigeria. Oryx, 29, 115-122

Oates, J.F. (1999) Myth and Reality in the Rain Forest: How Conservation Strategies Are Failing in West Africa. University of California Press, Berkeley.

Oates, J.F., Abedi-Lartey, M., McGraw, W.S., Struhsaker, T.T. \& Whitesides, G.H. (2000) Extinction of West African red colobus monkey. Conservation Biology, 14, 1526-1532.

Parren, M.P.E. \& de Graaf, N.R. (1995) The Quest for Natural Forest Management in Ghana, Côte d'Ivoire and Liberia. The Tropenbos Foundation, Wageningen.

Radovich, J. (1981) The collapse of the California sardine fishery: what have we learned? In Resource Management and Environmental Uncertainty (eds M.H. Glantz \& J.D. Thompson), pp. 107-136. John Wiley \& Sons, New York.
Robinson, J.G. \& Bennett, E.L. (2000a) Carrying capacity limits to sustainable hunting in tropical forests. In Hunting for Sustainability in Tropical Forests (eds J.G. Robinson \& E.L. Bennett), pp. 13-30. Columbia University Press, New York.

Robinson, J.G. \& Bennett, E.L. (eds) (2000b) Hunting for Sustainability in Tropical Forests. Columbia University Press, New York.

Robinson, J.G. \& Redford, K.H. (1986) Intrinsic rate of natural increase in Neotropical forest mammals: relationship to phylogeny and diet. Oecologia, 68, 516-520.

Sayer, J.A. (1977) Conservation of large mammals in the Republic of Mali. Biological Conservation, 12, 245-262.

Struhsaker, T.T. \& Oates, J.F. (1995) The biodiversity crisis in south-western Ghana. Primates, 1, 5-6.

Tutin, C.E.G. \& Fernandez, M. (1987) Gabon: a fragile sanctuary. Primate Conservation, 8, 160-161.

United Nations (2000) 1998 Demographic Yearbook. United Nations, New York.

White, F. (1983) The Vegetation of Africa. UNESCO, Paris.

White, L.J.T. (1994) Biomass of rain forest mammals in the Lope Reserve, Gabon. Journal of Animal Ecology, 63, 499-512.

Wilkie, D.S. \& Carpenter, J.F. (1999) Bushmeat hunting in the Congo Basin: an assessment of impacts and options for mitigation. Biodiversity and Conservation, 8, 927-955.

Wilkie, D.S., Sidle, J.G. \& Boundzanga, G.C. (1992) Mechanised logging, market hunting, and a bank loan in Congo. Conservation Biology, 6, 570-580.

\section{Biographical sketch}

Richard Barnes received his BSc in Ecology and Resource Management from the University of Edinburgh and his $\mathrm{PhD}$ from the University of Cambridge, UK. He is an Ecologist in Conservation International's Africa Program and a Visiting Scholar in the Biology Division at the University of California at San Diego. 